\title{
Biogas production from agricultural and municipal waste
}

\author{
Monika Kuźnia ${ }^{1, *}$, Anna Magiera $^{1}$, Wojciech Jerzak ${ }^{1}$, Kinga Pielichowska ${ }^{2}$, and Jakub \\ Sikora ${ }^{3}$ \\ ${ }^{1}$ AGH University of Science and Technology, Faculty of Metals Engineering and Industrial Computer \\ Science, Department of Heat Engineering and Environment Protection, 30 Mickiewicza Av., 30-059 \\ Krakow, Poland \\ ${ }^{2}$ AGH University of Science and Technology, Faculty of Materials Science and Ceramics, \\ Department of Biomaterials and Composites, 30 Mickiewicza Av., 30-059 Krakow, Poland \\ ${ }^{3}$ University of Agriculture in Krakow, Faculty of Production and Power Engineering, Institute of \\ Agricultural Engineering and Informatics, 116B Balicka Street, 30-149 Krakow, Poland
}

\begin{abstract}
The article presents the results of biogas production from municipal and agricultural waste. The mesophilic digestion of feedstocks was evaluated. Fermentation process was performed according to the DIN 38414-S8. Five types of agricultural waste were used for the research: $100 \%$ maize silage, $25 \%$ apple pomace $-75 \%$ maize silage, $50 \%$ apple pomace $50 \%$ maize silage, $75 \%$ apple pomace $-25 \%$ maize silage and under - size fraction of municipal waste from the sorting drum. Fermentation of waste was carried out for 30 days. In the produced biogas, there were measured the content of: $\mathrm{CH}_{4}, \mathrm{CO}_{2}, \mathrm{O}_{2}$ and the total yield of biogas. The combination of different groups of waste in the fermentation process causes a higher efficiency of biogas production. Additionally thermal analysis (TG, DSC) of biogas digestate were conducted. Due to the impurities present in the biogas digestate derived from municipal waste, it becomes impossible to use it as fertilizer in agriculture.
\end{abstract}

\section{Introduction}

Biogas is formed during anaerobic fermentation of organic wastes from agricultural, industrial and municipal waste. The fermentation of organic feedstock produces a biogas and digestate. Biogas is a gas mixture. Depending on the type of raw material used for anaerobic fermentation, the methane content ranges between $50-75 \%$. The second main biogas component is carbon dioxide. In addition, biogas contains nitrogen, hydrogen sulfide, ammonia and hydrogen [1]. Biogas can be directly used by combustion in Combined Heat and Power units (CHP).After reprocessing to natural gas quality biogas can be compressed to CBG (Compressed Bio Gas) and liquefied to LBG (Liquid Bio Gas). These are ideal fuels for cars, buses and trucks, especially in urban areas, because they produce virtually no particulate matter or $\mathrm{NO}_{x}$ emissions. Use of $\mathrm{CBG}$ is growing rapidly in Scandinavia [2-5]. Digestate is a byproduct in biogas plants. To date, $95 \%$ of the digestate produced in Europe

\footnotetext{
* Corresponding author: kuznia@agh.edu.pl
} 
is used as an organic fertilizer [6]. If the digestate cannot be used for field fertilization, due to exceeding the permissible content of contaminants, the presence of cullet, plastic waste or pathogenic bacteria, methods allowing their energy use can be used. The utilization of digestate may be an additional activity of a biogas plant.

Thermochemical methods of digestate utilization are: combustion, pyrolysis, gasification and hydrothermal carbonization (HTC). The processed digestate can be used as fuel. Before energy use, the dried digestate can be granulated to form pellets. It enables automation of the combustion process, reduction of fuel volume, limitation of water content, facilitates transport, storage and dosing. To reduce the cost of drying, the excess of waste heat generated in the biogas plant can be used. Also, the electricity needed for pelleting can be obtained from biogas plant. The obtained pellets can be used directly in combustion process. The calorific value of the dried digestate amounts to a dozen or so $\mathrm{MJ} / \mathrm{kg}$. For example, pellets made of maize silage, grasses and potatoes have a calorific value equal to $15.8 \mathrm{MJ} / \mathrm{kg}$ with a water content of $9.2 \%$ [3]. Another thermochemical process is pyrolysis, in which, apart from the pyrolysis gas, a charcoal called biochar is obtained. The gasification process produces a syngas whose main components are $\mathrm{CO}$ and $\mathrm{H}_{2}$. The drying of the digestate is not necessary when using the hydrothermal carbonization process (HTC). This process is carried out at $180-250^{\circ} \mathrm{C}$ at a pressure of $10-40$ bar.

The application of pelletized digestate as fuel are reported in literature [7-10]. Generally only agricultural digestate is used. The problem appears with utilization of municipal digestate. In many countries, despite the use of waste segregation, there is still no collection of biodegradable waste. Therefore, a large number of them goes to municipal waste that is not segregated. Finally, it is in the underside fraction, which can be successfully fermented in order to obtain biogas. The problem, however, is the digestate containing impurities that prevent its use as a fertilizer. The anaerobic stabilization processes for different wastes were evaluated using thermal analysis [11-13].

The purpose of the article was to compare the amount and composition of biogas produced during the fermentation of agricultural waste and the undersized fraction of municipal waste. Maize silage, apple pomace and mixtures thereof were used as agricultural feedstock.

In addition, two types of digestate (agricultural and municipal) were compared using thermal analysis.

\section{Materials and methods}

\subsection{Biogas production}

5 types of waste were used for the research: $100 \mathrm{wt} \%$ maize silage, $25 \mathrm{wt} \%$ apple pomace $-75 \mathrm{wt} \%$ maize silage, $50 \mathrm{wt} \%$ apple pomace $-50 \mathrm{wt} \%$ maize silage, $75 \mathrm{wt} \%$ apple pomace $-25 \mathrm{wt} \%$ maize silage and under-size fraction of municipal waste from the sorting drum.

Fermentation process of the investigated waste was carried out for 30 days, according to the DIN 38414-S8. During the fermentation process the following parameters were recorded: moisture, temperature, pressure, volume of biogas, the concentration of methane $\left(\mathrm{CH}_{4}\right)$, oxygen $\left(\mathrm{O}_{2}\right)$ and carbon dioxide $\left(\mathrm{CO}_{2}\right)$. A schematic representation of the test stand is shown in Figure 1. Fermentation devices were installed in a container filled with water with regulated temperature. Inside were placed 4 containers (1) with substrates. Controlling of temperature took place by means of an ESCO ES-20 electronic thermostat (unit switch 16A) with precision up to $\pm 0.2^{\circ} \mathrm{C}$ resulting from hysteresis of a sensor. Temperature decreases by value exceeding $0.1^{\circ} \mathrm{C}$ triggered a heater of $1500 \mathrm{~W}(2)$ and a simultaneous start-up of a 
Hanning DPO 25-205 water pump (3) in order to ensure a uniform distribution of temperature in the whole chamber. After heating water to the temperature exceeding the set temperature by $0.1^{\circ} \mathrm{C}$ the heater switches off and with a 30 seconds delay so does the pump. Separators combined in a row along with cut-off valves (4) and a manometer (5) which measures pressure in particular measuring branches constituted a switch board (6). The system of measuring volume (7) was composed of two columns filled with water with drain valves and a container for filling up the liquid level in columns (8). The measuring system was combined with a switchboard and a biogas composition meter (9). For each researched batch, fermentation was carried out simultaneously. The amount of gas produced was read out twice a day at the same time [1].

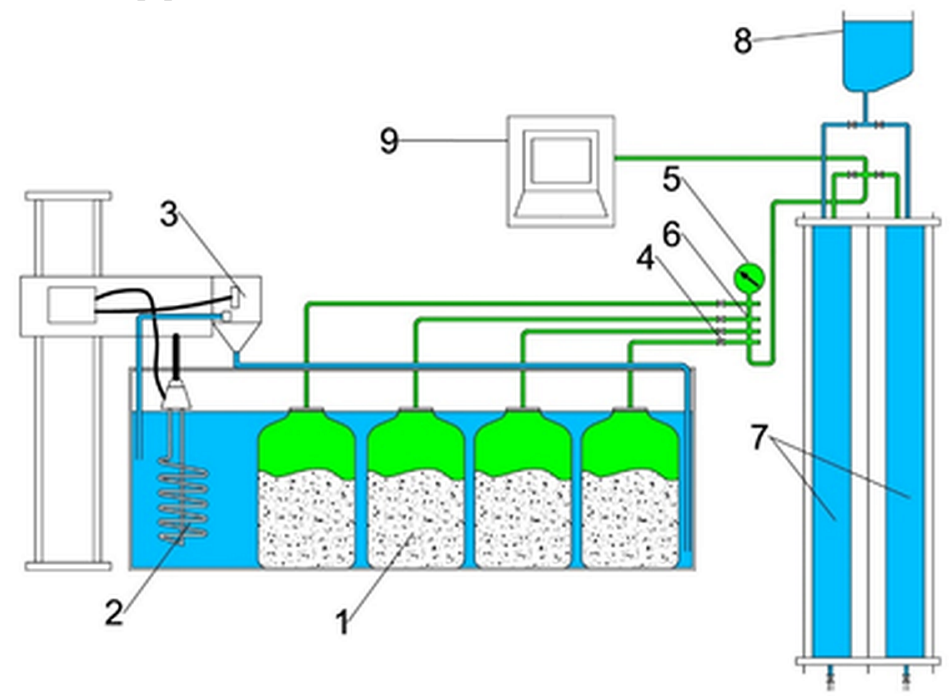

Fig. 1. A schematic representation of the test stand with a 2 liter fermenter.

\subsection{Analysis of digestate}

For two digestate samples (maize silage and under-sieve fraction of municipal waste) thermal analysis was performed. Thermogravimetric analysis (TG) is a technique based on the weight lost by a sample under heating in a controlled atmosphere. Differential Scanning Calorimetry (DSC) is based on the temperature changes in the sample as compared to an inert sample in the same rate of heating. Thermal properties of digestates were analysed by Differential Scanning Calorimetry analyzer DSC1 (Mettler-Toledo, Switzerland) and Thermogravimetric analyzer TGA 550 Discovery (TA Instruments, USA). The samples were heated in an air atmosphere to $600^{\circ} \mathrm{C}$ at a rate of 10 degrees $/ \mathrm{min}$. Additionally, the contents of carbon, hydrogen and nitrogen were determined. Analyses were performed on the analyzer LECO CHN 628.

\section{Results and discussion}

\subsection{Biogas production}

Mesophilic fermentation of analysed feedstocks was carried out for 30 days. The values of total biogas yield, average concentration of methane in biogas and productivity of biomethane are presented in the Table 1. The total yield of biogas from five groups of 
substrates (Fig. 2) and content of methane (Fig. 3), carbon dioxide (Fig. 4) and oxygen (Fig. 5) were monitored.

Table 1. Total biogas yield, average concentration of $\mathrm{CH}_{4}$ in biogas and productivity of biomethane.

\begin{tabular}{|c|c|c|c|}
\hline Material & $\begin{array}{c}\text { Total biogas } \\
\text { yield, } \\
\mathrm{Ndm}^{3} / \mathrm{kg} \mathrm{DM}\end{array}$ & $\begin{array}{c}\mathrm{CH}_{4}, \\
\text { vol\% } \\
\text { (average } \\
\text { value) } \\
\end{array}$ & $\begin{array}{c}\text { Biomethane } \\
\text { productivity } \\
\left(\mathrm{Ndm}^{3} / \mathrm{kg}\right. \\
\mathrm{DM})\end{array}$ \\
\hline Municipal waste, $100 \mathrm{wt} \%$ & 151 & 39.8 & 60.1 \\
\hline Maize silage, $100 \mathrm{wt} \%$ & 248 & 48.7 & 120.8 \\
\hline $25 \mathrm{wt} \%$ apple pomace- $75 \mathrm{wt} \%$ maize silage & 203 & 50.2 & 101.9 \\
\hline $50 \mathrm{wt} \%$ apple pomace- $50 \mathrm{wt} \%$ maize silage & 195 & 53.8 & 104.9 \\
\hline $75 \mathrm{wt} \%$ apple pomace- $25 \mathrm{wt} \%$ maize silage & 184 & 26.4 & 48.6 \\
\hline
\end{tabular}

The largest amount of biogas was produced during fermentation of maize silage (248 $\mathrm{Ndm}^{3} / \mathrm{kg} \mathrm{DM}, 48.7 \mathrm{vol} \% \mathrm{CH}_{4}$ ). After converting to biomethane the largest amount was also in this case $\left(120.8 \mathrm{Ndm}^{3} / \mathrm{kg} \mathrm{DM}\right)$. Due to the fact that the fermentation of maize silage generates large amounts of biogas with a high methane content, it is widely used as a feedstock in biogas plants. In a dry mass of maize, the corncob is $45-50 \%$ and $50-55 \%$ socalled green mass. The green part of the maize consists mainly of a fiber consisting of cellulose, hemicellulose and lignin, which only to some extent are degraded by bacteria. The most difficult is the fermentation of lignin, the amount of which depends on the phase of the plant's maturity. The older the plant, the higher the lignin level. Therefore, mature maize should not be used for the fermentation process. The addition of apple pomace to maize silage reduced the amount of biogas generated. The addition of apple pomace (up to $50 \mathrm{wt} \%$ ) to maize silage did not increase the amount of biogas (195 Ndm $3 / \mathrm{kg} \mathrm{DM})$ but improved its quality (48.7 vol\% $\mathrm{CH}_{4}$ ). In this case biomethane productivity was $104.9 \mathrm{Ndm}^{3} / \mathrm{kg} \mathrm{DM}$. In many cases, co-fermentation improves the quality and/or the amount of biogas. Fermentation of under-size fraction of municipal waste generated $60.1 \mathrm{Ndm}^{3}$ biomethane/ $\mathrm{kg} \mathrm{DM}$ and the value is higher than for the feedstock consisting of $75 \mathrm{wt} \%$ apple pomace- $25 \mathrm{wt} \%$ maize silage $\left(48.6 \mathrm{Ndm}^{3}\right.$ biomethane/kg DM). In the analysed feedstock of the municipal waste, there was a lot of glass cullet and small plastic elements which could reduce the amount of biogas.

Besides the main (measured) components, biogas also contains a lot of trace compounds. Many volatile organic compounds (VOCs) including organic silicon compounds, halogenated compounds and sulphur compounds are harmful to the environment (destruction of the ozone layer, the greenhouse effect) and they can cause damage to the biogas plant installations. Organic silicon compounds oxidized during combustion of biogas into microcrystalline silicon dioxide, similar to glass. Silicon dioxide deposits can cause destruction and corrosion of machines. Presence of halogenated compounds in biogas can cause formation of dioxins and furans during combustion process. The content of sulfur compounds in biogas is significant. The main sulphur compound in biogas is hydrogen sulphide $\left(\mathrm{H}_{2} \mathrm{~S}\right)$. Other sulphur compounds, which can also be found in biogas are: sulphides, disulphides and thiols. In a wet environment sulphur compounds can cause corrosion of metal elements. 


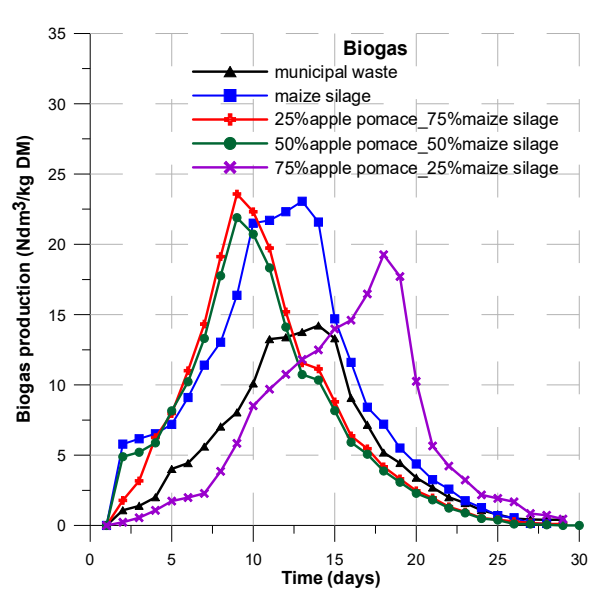

Fig. 2. Biogas production.

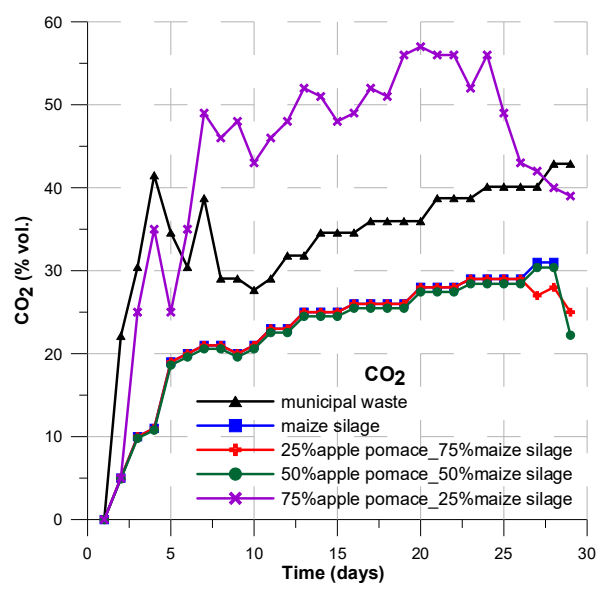

Fig. 4. Concentration of $\mathrm{CO}_{2}$ in biogas.

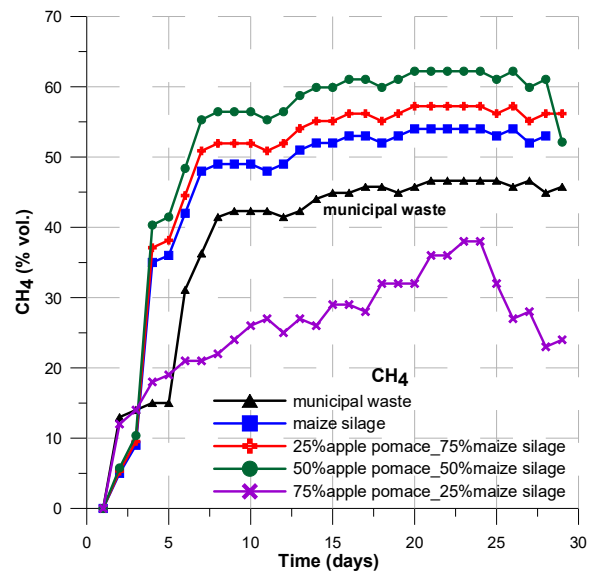

Fig. 3. Concentration of $\mathrm{CH}_{4}$ in biogas.

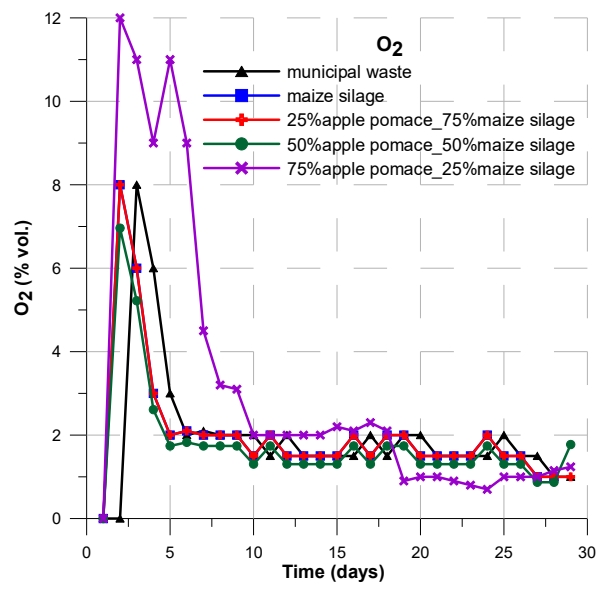

Fig. 5. Concentration of $\mathrm{O}_{2}$ in biogas.

\subsection{Analysis of digestate}

Table 2 presents the results of elemental analysis of digestates. The carbon content of maize silage (44.8\%) is similar to that in agricultural or forest biomass. Significantly lower carbon content in the digestate from municipal waste $(25.2 \%)$ is caused by the presence of inert contaminants, mainly glass pieces. However, the higher content of nitrogen $(2.11 \%)$ is due to the presence of leftover food with high protein content (e.g. fish), which in its structure contain, among others, nitrogen.

Table 2. Elemental analysis of digestates.

\begin{tabular}{|c|c|c|c|}
\hline Digestate & $\mathbf{C}, \mathbf{w t} \%$ & $\mathbf{H}, \mathbf{w t} \%$ & $\mathbf{N}, \mathbf{w t} \%$ \\
\hline Municipal waste & 25.2 & 3.00 & 2.11 \\
\hline Maize silage & 44.8 & 6.09 & 1.25 \\
\hline
\end{tabular}

Thermal analysis (TG, DSC) of maize silage digestate (Fig. 6) and municipal waste digestate (Fig. 7) were carried out. DTG (Derivative Thermogravimetry) curves showed the rate of decomposition. TG curve of maize silage digestate showed three main steps of weight 
loss in the temperature range between 25 and $600{ }^{\circ} \mathrm{C}$. The first peak, in the range of 30-160 ${ }^{\circ} \mathrm{C}$ is associated with the dehydration process. The second peak, between $220-380{ }^{\circ} \mathrm{C}$ is attributed to the easily oxidizable compounds (e.g. cellulosic material and aliphatic structures) [14]. The third step, between $400-600^{\circ} \mathrm{C}$, is due to the thermal degradation of recalcitrant, aromatic structures including lignin and non-hydrolyzable compounds [15]. Temperature at which $50 \%\left(\mathrm{TG}-\mathrm{T}_{50}\right)$ of weight loss occurred in maize silage digestate is $313{ }^{\circ} \mathrm{C}$. Finally, the amount of mass remained was $6.28 \%$. Energy effects are visible on the DSC curve. The endothermic peak is located in the area of water evaporation. The remaining peaks are exothermic peaks associated with the combustion process of the maize silage digestate.

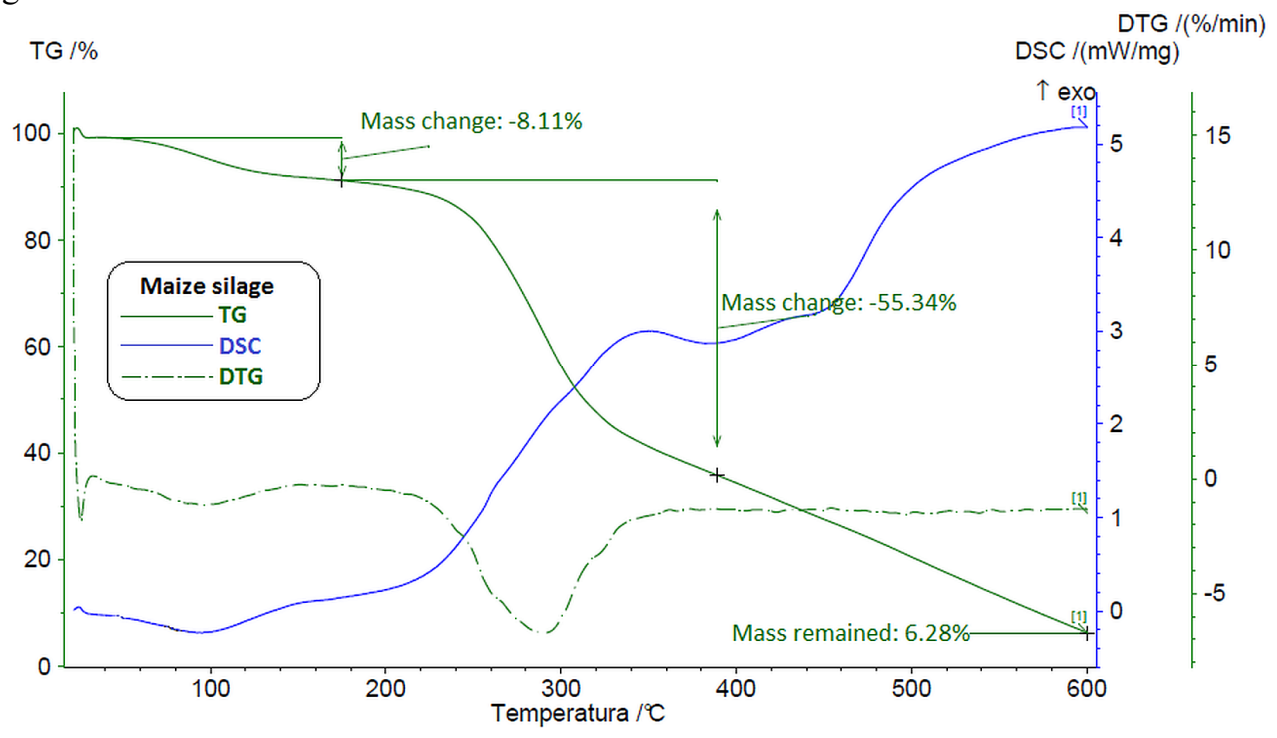

Fig. 6. TG, DTG and DSC curves of maize silage digestate.

Thermal degradation of municipal waste digestate (Fig. 7) runs a little differently. This is related to the presence of small pieces of plastics waste. The most important and the most frequently used plastics are polyethylene (PE) and polypropylene (PP). Therefore, large quantities of plastic are found in the municipal waste fraction (even after the home segregation process). The first stage of oxidation $\left(180-380^{\circ} \mathrm{C}\right)$ is associated with the presence of food residues and the beginning of degradation of plastics. Thermal decomposition of plastic begins at a temperature of approx. $250{ }^{\circ} \mathrm{C}$ and ends at approx. $550{ }^{\circ} \mathrm{C}$, except the temperature at the end of decomposition of polypropylene, which is appox. $400{ }^{\circ} \mathrm{C}[16]$. The beginning of the process of decomposition can be caused by the combustion of compounds from an alkanes group, whose temperature of spontaneous combustion is lower than $250{ }^{\circ} \mathrm{C}$ (e.g. n-hexane and n-heptane, n-octane, n-nonane, n-decane, n-undecane). These compounds are products of the main chain of polymer splitting. Further stages in the process of decomposition are associated with the process of compound combustion, which includes: $n$ butane, 1,3-butadiene, ethane and ethylene, and these gases occur at a temperature of approx. $350{ }^{\circ} \mathrm{C}, 400{ }^{\circ} \mathrm{C}$ and $450{ }^{\circ} \mathrm{C}$ [16]. There are also present the combustible compounds with higher (than $450{ }^{\circ} \mathrm{C}$ ) ignition temperature such as: $\mathrm{CH}_{4}, \mathrm{CO}$ and $\mathrm{C}_{6} \mathrm{H}_{6}$ [16]. Temperature at which $50 \%\left(\mathrm{TG}-\mathrm{T}_{50}\right)$ of weight loss occurred in municipal waste digestate is $552{ }^{\circ} \mathrm{C}$. The amount of mass remained was $46.07 \%$. A significant amount of mass remained was glass waste. DSC profile was characterized by two exothermic peaks, one in the range $200-320{ }^{\circ} \mathrm{C}$ corresponding to the degradation of the easily biodegradable fraction (carbohydrates, dehydration of aliphatic structures and decarbolixation of cellulose) [14] and the beginning 
of degradation of plastics. The second exothermic peak around $400-580^{\circ} \mathrm{C}$, was associated with the degradation of aromatic structures from organic polymers.

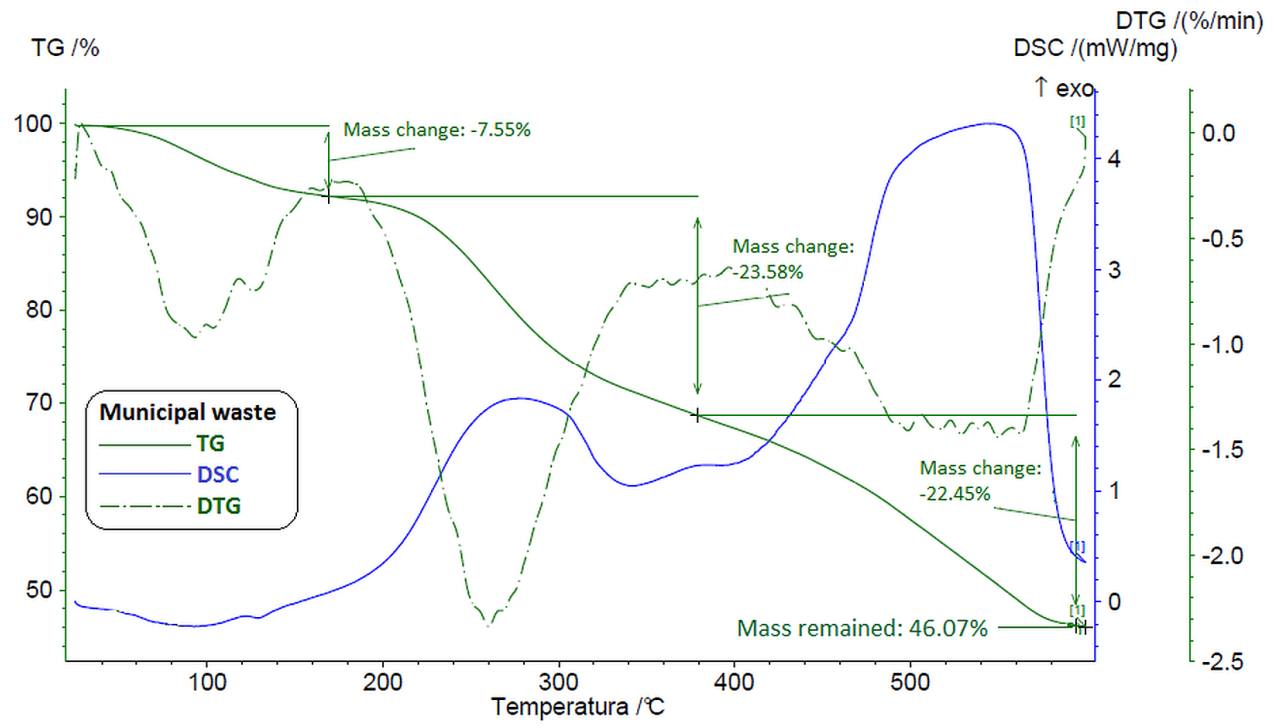

Fig. 7. TG, DTG and DSC curves of municipal waste digestate.

\section{Conclusions}

Fermentation of agricultural waste generates large quantities of good quality biogas. There is no problem with agricultural digestate, which is used as a fertilizer.

Fulfilling several conditions, it is possible to use under-size fraction of municipal waste in biogas plants. In order to increase the amount and quality of biogas, the interesting solution seems to be to operate the co-fermentation process of municipal waste and agricultural waste (e.g. maize silage). Additionally, the presence of physical impurities can cause problems such as perturbation of operation stability. However, it would be necessary to separate waste glass, gravel and metals. Non-digestible materials can also be removed with the use of physical barriers such as screens, sieves and stone traps. This would enable the energetic use of a digestate. The carbon content and the calorific value of the digestate would increase. It could be dried and pelleted and used for industrial or energy applications (such as co-combustion for CHP generation). To further improve the quality of biogas obtained from the fermentation of municipal waste a good solution would be to operate the co-fermentation process of municipal waste and agricultural waste.

The paper has been prepared under the AGH-UST statutory research grant No. 11.11.110.592.

\section{References}

1. W. Jerzak, M. Kuźnia, A. Szajding, Procedia Engineering 157, 222 (2016)

2. M. Kuźnia, W. Jerzak, P. Łyko, J. Sikora, Journal of Power Technologies 95, 158 (2015)

3. W. M. Budzianowski, Renewable and Sustainable Energy Reviews 16, 342 (2012)

4. W. M. Budzianowski, I. Chasiak, Journal of Power Technologies 91, 102 (2011)

5. B. Igliński, R. Buczkowski, A. Iglińska, M. Cichosz, G. Piechota, W. Kujawski, Renewable and Sustainable Energy Reviews 16, 4890 (2012) 
6. J. Dahlin, C. Herbes, M. Nelles, Resources, Conservation and Recycling 104152 (2015)

7. C.Y. Hung, W.T. Tsai, J.W. Chen, Y.Q. Lin, Y.M. Chang, Waste management 66, 53 (2017)

8. M. Kratzeisen, N. Starcevic, M. Martinov, C. Maurer, J. Müller, Fuel 89, 2544 (2010)

9. S. Pedrazzi, G. Allesina, T. Belló, C.A. Rinaldini, P. Tartarini, Fuel Processing Technology 130, 172 (2015)

10. M. Barbanera, F. Cotana, U. Di Matteo, Renewable Energy 121, 597 (2018)

11. B. Molinuevo-Salces, X. Gómez, A. Morán, M. C. García-González, Waste Management 33, 1332 (2013)

12. X. Gómez, M. J. Cuetos, A. I. García, A. Morán, Termochimica Acta 426, 179 (2005)

13. X. Gómez, M. J. Cuetos, A. I. García, A. Morán, Journal of Hazardous Materials 149, 97 (2007)

14. M. R. Provenzano, O. Cavallo, A. D. Malerba, C. Fabbri, Journal of Cleaner Production 193, 372 (2018)

15. M. Schnitzer, J. Hoffman, Soil Science Society of America, Proceedings 30, 63 (1966)

16. M. Kuźnia, A. Magdziarz, Chemical and Process Engineering 34, 165 (2013) 